Gut, 1973, 14, 683-688

\title{
Small intestinal permeability in animals and man
}

\author{
C. A. LOEHRY, J. KINGHAM, AND JUNE BAKER \\ From the Royal Victoria Hospital, Bournemouth
}

SUMMARY The permeability of the human small intestine has been studied by measuring the clearance from the plasma into the intestinal lumen of substances with molecular weights ranging from 60 to 80 000. A direct relationship has been demonstrated between intestinal loss and plasma concentration and an inverse one between clearance and molecular size.

The permeability of the rabbit small intestine has been studied at various levels by measuring the blood-to-lumen clearance of substances of different molecular size ranging from 60 to 40000 . It has been demonstrated that there is a progressive fall in permeability from the duodenum to the terminal ileum for all the substances studied.

\section{Part I Small intestinal permeability in man}

Although the prime function of the small intestine is that of absorption and the transfer of substances from the lumen into the body, a continuous flow in the reverse direction is also known to occur. These substances are derived from the plasma by direct permeation through the mucosa, but also pass out into the lumen in secretions from the gallbladder, pancreas, Paneth and goblet cells, or through desquamation of intestinal epithelial cells.

In previous experiments with rabbits (Loehry, Axon, Hilton, Hider, and Creamer, 1970) it has been demonstrated that the transfer of substances passing directly from the blood into the lumen is dependent directly upon their concentration in the plasma and inversely upon their molecular size. The aim of the present experiments was to study the blood-to-lumen flow of substances with different molecular size in man.

\section{Methods}

Two methods of study were used.

1 THE CLEARANCES OF UREA, URIC ACID, CREATININE, AND $\mathrm{CO}^{68}$ CYANOCOBALAMIN INTO A SEGMENT OF DUODENUM

A triple lumen tube was screened into the third and fourth parts of the duodenum. Saline, $0.9 \mathrm{~g} \%$, containing the unabsorbable marker polyethelene glycol

Received for publication 7 June 1973.
(PEG), $0.8 \mathrm{mg}$ per $\mathrm{ml}$, was infused by a constant flow pump through the middle tube. Collections were obtained from the proximal and distal tubes by siphonage. This method has been shown to be effective in studying loss of epithelial cells into the segment between the infusing and distal collecting sites, and a method of calculating absolute loss has been described (Croft, Loehry, Taylor, and Cole, 1968).

A group of 12 patients was studied, both normal and patients in varying degrees of renal failure providing different plasma concentrations of urea, uric acid, and creatinine. The levels of $\mathrm{Co}^{57}$ Cyanocobalamin were varied by injecting different amounts of the isotope intravenously into the subjects after an initial loading dose of $1000 \mu \mathrm{g}$ to saturate the protein-binding capacity of the plasma.

Tests were performed after a 12-hour fast and after a 30-minute priming infusion to ensure a good flow in all the tubes two 30-minute perfusions of $500 \mathrm{ml}$ were performed. Two blood samples were taken to estimate the plasma levels, one at the beginning and the other at the end of the two timed perfusions. The levels of urea, uric acid, and creatinine were measured by standard techniques and the level of $\mathrm{Co}^{57}$ was evaluated in a well type scintillation counter. The PEG in the perfusate was measured by the method of Hyden (1956). From the figures in the proximal and distal perfusates the total amount of the substances that were lost into the test segment was calculated (Croft et al, 1968) and the 
mean was taken between the two perfusions. The plasma level was the mean level of the two specimens taken at the beginning and end of the experiments.

2 EXCRETION OF PARENTERALLY ADMINISTERED ${ }^{125}$ I POLYVINYLPYRROLIDONE (PVP)

Fifty $\mu \mathrm{c}$ of ${ }^{125} I$-labelled PVP was injected intravenously into six patients with no evidence of gastrointestinal disease. Blood was taken 30 minutes after injection and the stools were collected over the next four days. The total stool collection was sterilized, homogenized, diluted, and filtered, and the filtrate concentrated by evaporation in cellophane bags. Two ml samples of plasma and stool filtrate were placed on a $76 \times 2 \mathrm{~cm}$ column of Sephadex G200 and eluted with $1 \%$ saline to which had been added $10 \mathrm{mg} \%$ sodium azide. Four $\mathrm{ml}$ fractions were collected in an automatic changer and the radioactivity was counted in a well-type scintillation counter. An early blood level was taken as it had been demonstrated in previous experiments that maximal loss into the intestinal lumen occurred within the first hour after injection of the isotope when the plasma levels were highest. The column used in these experiments was calibrated by measuring the elution volumes of proteins of known molecular weights-albumin, ovalbumin, and insulin.

\section{Results}

\section{PERFUSION EXPERIMENTS}

Figure 1 shows a graph relating the amounts of urea that were lost into the test segment to the levels of blood urea in the group of patients studied. It is clear that there is a direct relationship between the levels of urea in the intestinal lumen and the blood. A similar relationship was established for the other

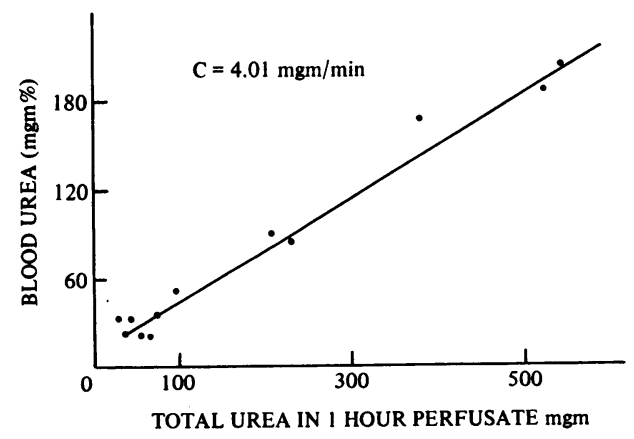

Fig 1 Comparison of blood urea with the amount of urea in the intestinal perfusate in 12 patients. substances studied. From these graphs the clearances of the substances into the intestinal lumen could be calculated as follows:

\section{Clearance $=$}

Amount of substance excreted per minute

Concentration of the substance in the plasma

As the relationship between the plasma and intestinal levels remained constant over the range studied, the plasma clearance corresponds to the reciprocal of the slope of the line.

The individual clearances for all the substances are listed in table I. It can be seen that the smaller

\begin{tabular}{llc}
\hline & Clearance $(\mathrm{ml} / \mathrm{min})$ & Molecular Weight \\
\hline Urea & 4.01 & 60 \\
Creatinine & 1.04 & 120 \\
Uric acid & 0.45 & 168 \\
Vitamin B $_{12}$ & 0.051 & 1350 \\
\hline
\end{tabular}

Table I Intestinal clearance and molecular size of the substance measured in the blood and intestinal lumen

molecules are cleared at a much faster rate than the larger ones. Figure 2 demonstrates the relationship between molecular weight and intestinal clearance on a logarithmic scale and shows an inverse relationship between clearance and molecular weight.

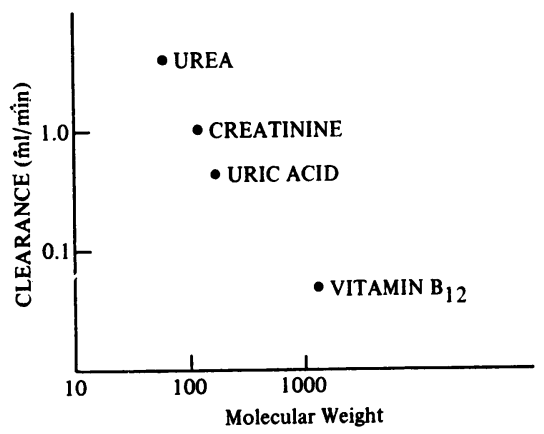

Fig 2 Clearance compared with molecular size on a logarithmic scale.

EXPERIMENTS WITH ${ }^{125} 1$ PVP

A similar relationship was established in the experiments with ${ }^{125}$ I PVP. Figure 3 demonstrates the radioactivity in the fractions of decreasing molecular size as they came off the column, both in the plasma and in the stools, and shows a relative increase in radioactivity in the smaller molecular weight fractions in the faeces. From these results it was possible to calculate the intestinal clearance for 


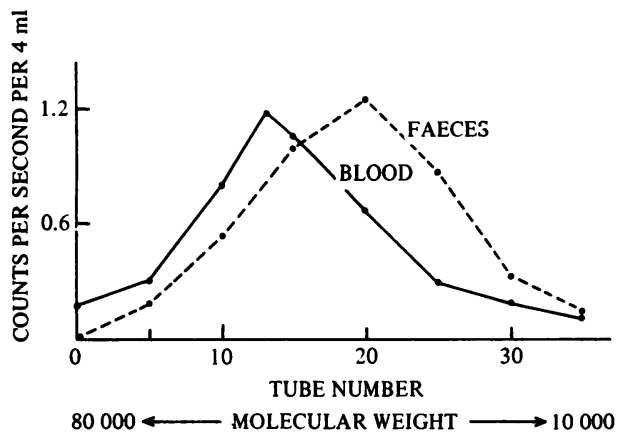

Fig 3 Radioactivity (counts per second) in different molecular weight fractions of ${ }^{125} I$ PVP.

each molecular weight fraction and these clearances are demonstrated in figure 4. Once again there is a

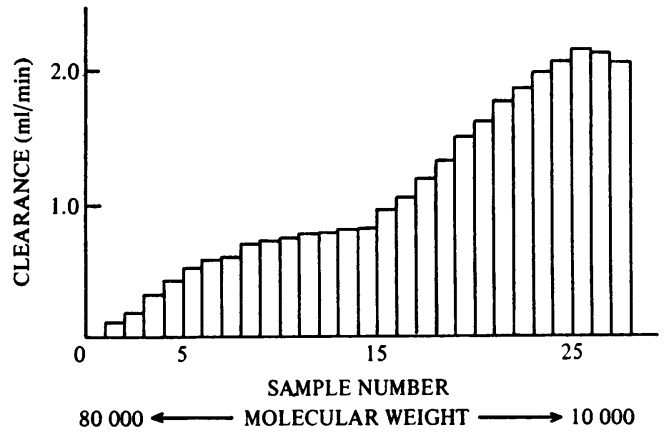

Fig 4 Intestinal clearance compared with molecular size in different molecular weight fractions of ${ }^{125} I P V P$.

progressive rise in intestinal clearance with a fall in molecular size.

\section{Part II Permeability differences in the upper and lower small intestine of the rabbit}

Previous studies on both rabbits and man have demonstrated that the blood-to-lumen flow of substances with molecular weights ranging from 60 to 80000 was dependent directly upon the concentration of the substances in the plasma and inversely upon their molecular size (Loehry et al, 1970). These studies were concerned with the clearance into the whole small intestine or into a single perfused segment of human duodenum. The work of Fordtran et al, using the movement of water into the human small intestine in response to osmotic gradients by solutes of different molecular size, has demonstrated that in man the permeability of the small intestine decreases progressively from the jejunum to the ileum, suggesting that the effective 'pore' radius in the upper jejunum is twice that in the lower ileum (Fordtran, Rector, Ewton, Soter, and Kinney, 1965). The aim of the present experiments was to study the difference in permeability in the upper and lower small intestine of the rabbit by direct measurement of the blood-tolumen clearance of substances of different molecular size.

\section{Methods}

The experiments were performed on albino rabbits weighing 2.5 to $3.5 \mathrm{~kg}$ under nembutal anaesthesia.
The ear vein was cannulated for injection of the test substances and the carotid artery for the collection of blood samples. The abdomen was opened by a mid-line incision and both renal pedicles were tied off to prevent the loss of the injected substances into the urine. The intestine was perfused by a constant flow pump with normal saline at a temperature of $40^{\circ} \mathrm{C}$. Urea, creatinine, and xylose were measured by standard techniques, and $\mathrm{Co}^{57} \times$ cyanocobalamin and ${ }^{125}$ I polyvinylpyrrolidone (PVP) counted in a well-type scintillation counter.

\section{PERFUSION OF JEJUNAL AND ILEAL SEGMENTS}

Two 20-inch segments of small intestine were cannulated, the upper one beginning at the ligament of Treitz and the lower one 20 in. proximal to the ileocaecal valve. Perfusions were performed at the rate of $350 \mathrm{ml}$ per hour. After preliminary perfusion to clear the bowel of faecal material a mixture of the test substances was injected intravenously. The test mixture was made up of $8 \mathrm{~g}$ of urea, $3 \mathrm{~g}$ of creatinine, $40 \mu \mathrm{c}$ of ${ }^{125} \mathrm{I}$ PVP, and $3 \mu \mathrm{c}$ of $\mathrm{Co}^{57}$ vitamin $\mathrm{B}_{12}$ in $15 \mathrm{ml}$ of normal saline. Before the start of the experiments the animals received $100 \mu \mathrm{g}$ of unlabelled vitamin $B_{12}$ intravenously. Increasing amounts of the test mixture were injected intravenously and after a 
15-minute equilibration period a blood sample was taken and a timed 30 perfusion begun. Six such perfusions were performed on each animal with gradually increasing amounts of the test mixture injected. The levels of the various substances in the perfusates were estimated and related to the average blood levels between the samples taken at the beginning and end of each perfusion.

\section{PERFUSION OF THE INTESTINE IN SEGMENTS}

After the initial experiments it was decided to perfuse small segments of intestine from the upper duodenum to the terminal ileum to build up a composite picture of permeability at different levels. Four-inch-long adjacent segments were perfused starting at the second part of the duodenum. In order to limit the amount of trauma only four segments were perfused in each animal and a total picture was built up over 12 experiments. As the segments were short the levels in the perfusate were found to be low and the fluid was therefore recycled through each segment and samples of the perfusate taken for analysis at the end of hourly periods up to three hours. In these experiments the test mixture contained $5 \mathrm{~g}$ xylose, $6 \mathrm{~g}$ urea, $3 \mathrm{~g}$ creatinine, and $50 \mu \mathrm{c}^{125} \mathrm{I}$ and the whole sample was injected at the beginning of the experiment.

\section{DIRECT INJECTION INTO THE MESENTERIC ARTERIAL SUPPLY}

Short 2-in. segments of duodenum and jejunum were cannulated and perfused at a rate of $600 \mathrm{ml}$ per hour. Two $\mathrm{ml}$ of a mixture of $8 \mathrm{~g}$ urea, $3 \mathrm{~g}$ creatinine, $40 \mu \mathrm{c}$ ${ }^{125} \mathrm{I}$ PVP, and $3 \mu \mathrm{c} \mathrm{Co}{ }^{57}$ vitamin $\mathrm{B}_{12}$ was injected directly into the radical of the mesenteric artery supplying the loops and the perfusate collected at 10 -sec intervals for 10.5 minutes.

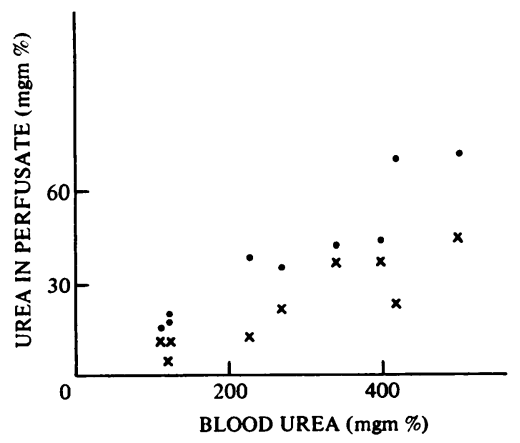

Fig 5 Comparison of blood urea with amount of urea in the perfusate from jejunal and ileal loops. Jejunum; $\times$ ileum.

\section{Results}

PERFUSION OF JEJUNAL AND ILEAL SEGMENTS

In all cases there was a rise in the perfusate levels of thesubstances concomitantly with an increasing blood level, though the levels in the jejunal segment were always higher than in the ileal one. Figure 5 demonstrates the results for urea in both segments. Although the perfusate levels increased, the clearances in jejunum and ileum remained constant over the range of plasma levels studied, and fig 6 demonstrates these where

\section{Clearance $=$}

amount of substance excreted per 15-min perfusion amount of substance in $1 \mathrm{ml}$ of plasma

Table II shows the jejunal and ileal clearances for all

\begin{tabular}{lcll}
\hline Substance & $\begin{array}{l}\text { Average } \\
\text { Molecular Size }\end{array}$ & $\begin{array}{l}\text { Clearance } \\
\text { (ml/min) }\end{array}$ & $\begin{array}{l}\text { Ileal/Jejunal } \\
\text { Clearance }(\%)\end{array}$ \\
\hline${ }^{185} \mathrm{I}$ & 40000 & $\begin{array}{l}\text { Jejunum } 0.00554 \\
\text { Ileum } 0.00323\end{array}$ & 56.5 \\
$\mathrm{Co}^{57}$ vitamin $\mathrm{B}_{12}$ & 1300 & $\begin{array}{l}\text { Jejunum } 0.0153 \\
\text { Ileum } 0.0086\end{array}$ & 56.8 \\
Creatinine & 120 & $\begin{array}{l}\text { Jejunum } 0.0336 \\
\text { Ileum } 0.0186\end{array}$ & 55.6 \\
Urea & 60 & $\begin{array}{l}\text { Jejunum } 0.134 \\
\text { Ileum } 0.083\end{array}$ & 62.0 \\
\hline
\end{tabular}

Table II Clearances of substances of different molecular size into jejunal and ileal loops

the substances studied expressed in $\mathrm{ml} / \mathrm{min}$ and also demonstrates the relationship of the ileal to the jejunal levels. It is clear that the proportionate fall in clearance in all the substances in the ileum remained constant for all the substances with molecular size ranging from 60 to 40000 . This would suggest that

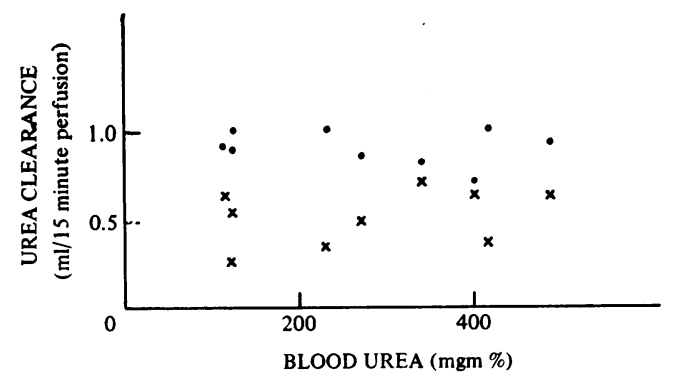

Fig 6 Intestinal clearance of urea into jejunal and ileal loops with increasing blood urea. Jejunum; $\times$ ileum. 
the distribution of pores in the ileum is similar to that in the jejunum but that there were fewer of them present.

\section{PERFUSION OF INTESTINE IN SEGMENTS}

Figure 7 demonstrates the intestinal clearances of ${ }^{125}$ I PVP, xylose, urea, and creatinine into the 4-inch segments of small intestine from the second part of the duodenum down to the terminal ileum. With all the substances there was a fall from the proximal to the distal intestine, the greatest fall occurring in the first $\mathbf{4 0} \mathrm{in}$. and then to a lesser extent in the last $\mathbf{4 0}$ inches.

\section{DIRECT INJECTION INTO THE MESENTERIC}

ARTERIAL SUPPLY

Figure 8 demonstrates the levels of ${ }^{125}$ I PVP in the perfusate after injection of the isotope into a mesenteric radical in the jejunum and ileum. The curves for the other substances studied-urea, creatinine, vitamin $B_{12}$, and ${ }^{59} \mathrm{Fe}$-were all similar and the peak excretion of all the substances was rapidly reached in $1 \mathrm{~min} 30$ $\mathrm{sec}$ to $2 \mathrm{~min}$ after injection, and therefore molecular size clearly made no difference to the speed with which the molecules permeated the mucosal barrier.

\section{Discussion}

The concept of permeability of the small intestinal mucosa is not a new one, and Fordtran et al formulated the pore hypothesis, proposing that the mucosal wall was lined by a fat-soluble membrane perforated

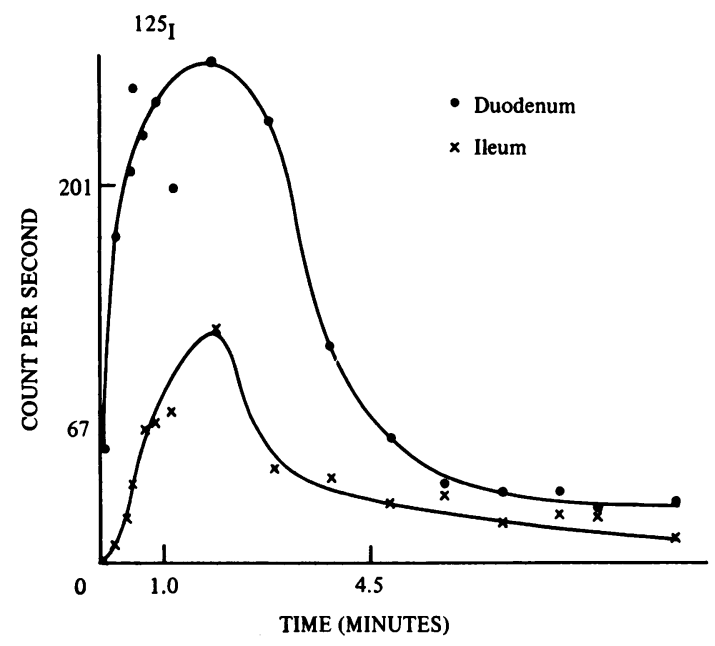

Fig 8 Levels of ${ }^{125} I$ PVP in short jejunal and ileal segments after direct injection into the mesenteric arterial supply. Duodenum, $\times$ ileum.

with water-filled pores whose diameter lay between 3 and $8.8 \AA$ (Fortdran et al, 1965). However, it is also recognized that substances whose size is greatly in excess of this can permeate the intestinal mucosa (Cornell, Walker, and Isselbacher, 1971; Warshaw, Walker, Cornell, and Isselbacher, 1971), and one must therefore postulate the presence of some pores with a much greater diameter, or that some different mechanism exists for the passage of these large molecules. The results from the study on

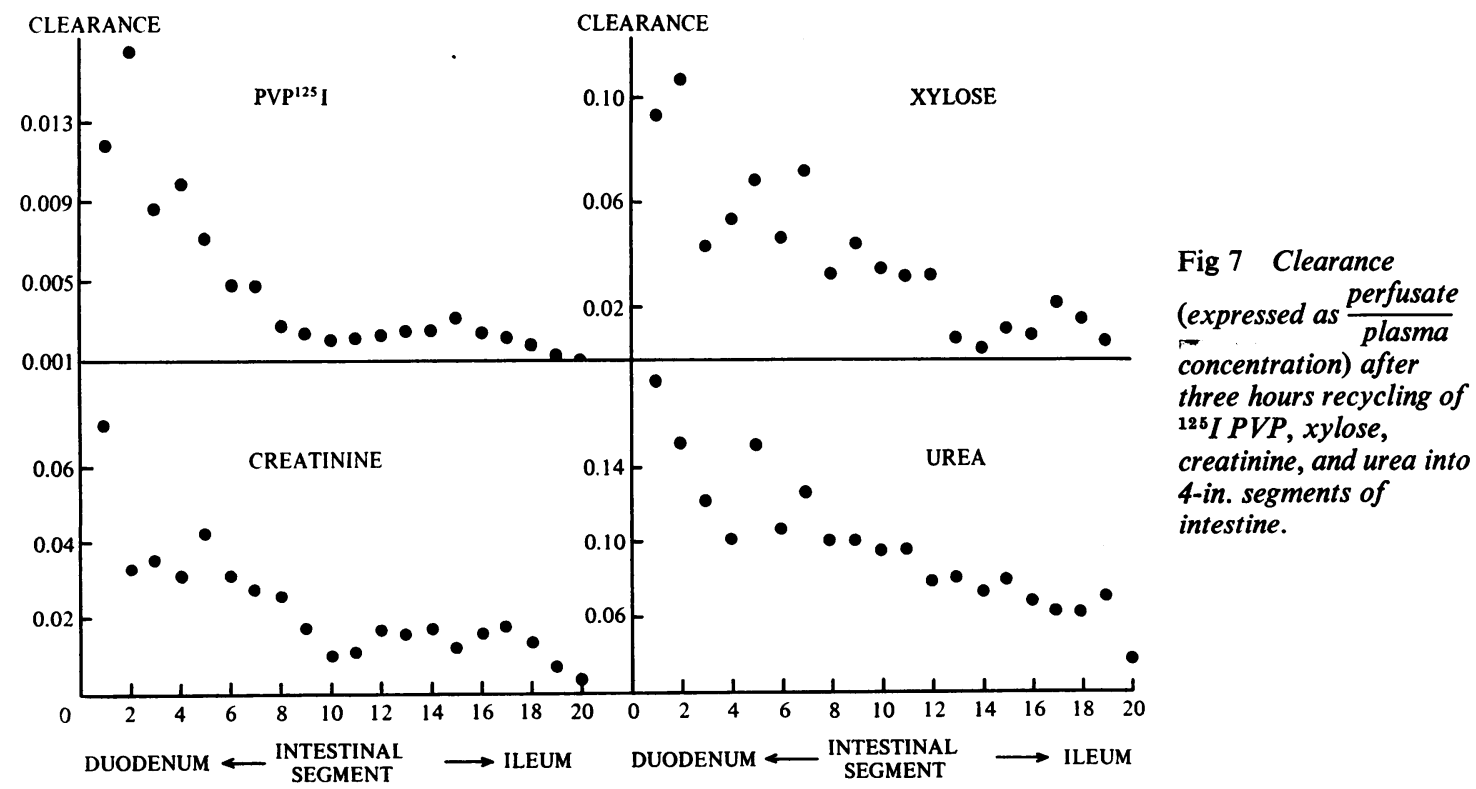


patients would support the former hypothesis, demonstrating a linear relationship between intestinal clearance and molecular size, with a fall in clearance with molecular sizes ranging from 60 to 80000 . In addition it is likely that the upper small intestine is more permeable than the lower (Fordtran et al, 1965) thus ensuring a constant internal environment in the upper intestinal lumen whatever the intake. The results of the present study support those of Fordtran et al (1965) and demonstrate that the permeability of the small intestine in the rabbit decreases progressively from upper duodenum to terminal ileum. This decrease in permeability was apparent for substances with molecular size ranging from 60 to 40000 , although the proportionate fall in permeability between the upper and lower intestine was constant over the whole range of molecular size. These results would suggest that the distribution of pores in the whole of the small intestine remains constant, ie, many small pores, a moderate number of medium-size pores, and very few large pores, but that the absolute number of pores of all sizes progressively decreases down the length of the small intestine. This concept was also supported in the experiments where the substances were injected directly into the mesenteric arterial supply as the peak level of the substances appearing in the lumen occurred at a similar time after injection in both jejunum and ileum though the absolute level was higher in the upper small intestine. The fact that the substances of different molecular sizes all passed through at similar times suggests that the mucosal barrier for all the substances is identical and that the same mechanism of permeation exists for substances of high as well as low molecular size.

The mechanism by which substances permeate the intestinal mucosa is not fully understood. It is theoretically possible that substances pass between epithelial cells, through them, or through gaps left by extruded cells at the tips of the villi. In fact, all of these routes may be used (Cornell et al, 1971; Warshaw et al, 1971; Hugon and Borgers, 1968; Loehry, Parish, and Baker, 1973). Preliminary results from autoradiographic studies are also in support of this hypothesis (Loehry and Baker, unpublished observations). In practice it seems unlikely that there is any significant difference between the extrusion zones in the jejunum and ileum or in the intercellular spaces. It is well recognized that the upper and lower intestine differ markedly in the absorption of salt and water (Hindle and Code, 1962; Fordtran and Dietschy, 1966) and it seems likely therefore that differences in permeability rest also in the intrinsic make up of the epithelial cell.

Although there are differences in the surface area between the upper and lower small intestine this in itself is not enough to account for the differences in permeability demonstrated by the present study. In the rat it has been shown that the relationship between the area of the mucosal surface and the length in the jejunum is approximately $25 \%$ greater than in the ileum (Fisher and Parsons, 1950), whereas the difference in clearance of these two levels in the present study has been shown to be between 50 and $60 \%$. This difference in permeability is of obvious physiological and pathological importance. In terms of absorption it would explain why substances which pass through the mucosa by passive diffusion are maximally absorbed in the upper small intestine. In terms of intestinal loss it is of obvious importance that the loss of molecules that are biologically important should be limited in the distal small intestine where there may be limited time available for reabsorption. Naturally under normal circumstances most of the substances lost into the lumen will be reabsorbed in their passage down the bowel and loss will be minimal. In disease states, however, there may be both increased exudation due to mucosal disease and increased loss due to intestinal hurry and also to diminished reabsorption. Under these circumstances it is possible that plasma clearance into the intestinal lumen plays a significant part in the production of deficiency states.

I am grateful to the Wessex Regional Board Research Committee for providing funds that have made this work possible.

References

Cornell, R., Walker, W. A., and Isselbacher, K. J. (1971). Small intestinal absorption of horseradish peroxidase. Lab. Invest., 25, $42-48$.

Croft, D. N., Loehry, C. A., Taylor, J. F. N., and Cole, J. (1968). DNA and cell loss from normal small intestinal mucosa. Lancet, 2 , 70-73.

Fisher, R. B., and Parsons, D. S. (1950). The gradient of mucosal surface area in the small intestine of the rat. J. Anat. (Lond.), 84, 272-282.

Fordtran, J. S., and Dietschy, J. M. (1966). Water and electrolyte movement in the intestine. Gastroenterology, 50, 263-285.

Fordtran, J. S., Rector, F. C. Jr., Ewton, M. F., Soter, N., and Kinney, J. (1965). Permeability characteristics of the human small intestine. J. clin. Invest., 44, 1935-1944.

Hindle, W., and Code, C. F. (1962). Some differences between duodenal and ileal sorption. Amer. J. Physiol., 203, 215-220.

Hugon, J. S., and Borgers, M. (1968). Absorption of horseradish peroxidase by the mucosal cells of the duodenum of the mouse. 1. The fasting animal. J. Histochem. Cytochem., 16, 229-236.

Hyden, S. (1956). A turbidometric method for the determination of higher polyethylene glycols in biological materials. $K$. Lantbr Högs. Annlr, 22, 139-145.

Loehry, C. A., Axon, A. T. R., Hilton, P. J., Hider, R. C., and Creamer B. (1970). Permeability of the small intestine to substances of different molecular weight. Gut, 11, 466-470.

Loehry, C. A., Parish, D., and Baker, J. (1973). Permeability of the small intestinal mucosa : a study using iron. Gut, 14, in press.

Warshaw, A. L., Walker, W. A., Cornell, R., and Isselbacher, K. J. (1971). Small intestinal permeability to macromolecules. Lab. Invest., 25, 675-684. 